\title{
Flora da Bahia: Nymphaeaceae
}

\author{
Carla Teixeira de Lima ${ }^{1 *}$, Ana Maria Giulietti ${ }^{1,2} \&$ Francisco de Assis Ribeiro Santos ${ }^{1}$
}

${ }^{1}$ Programa de Pós-Graduação em Botânica, Departamento de Ciências Biológicas, Universidade Estadual de Feira de Santana, Av. Transnordestina s/n, Novo Horizonte, 44.036-900, Feira de Santana, Bahia, Brasil.

${ }^{2}$ Royal Botanic Gardens, Kew, Richmond, Surrey, TW93AB, United Kingdom.

Resumo - É apresentado o levantamento florístico de Nymphaeaceae do estado da Bahia, Brasil. Foram reconhecidas seis espécies de Nymphaea: N. amazonum, N. caerulea, N. lasiophylla, N. lingulata, N. pulchella e N. rudgeana. É apresentada uma chave de identificação, além de descrições, ilustrações e comentários gerais para as espécies.

Palavras-chave adicionais: Brasil, florística, Nymphaea, plantas aquáticas, taxonomia.

\begin{abstract}
Flora of Bahia: Nymphaeaceae) - A floristic treatment of the Nymphaeaceae from Bahia State, Brazil, is presented. Six species of Nymphaea were recognized: N. amazonum, N. caerulea, N. lasiophylla, N. lingulata, $N$. pulchella and N. rudgeana. An identification key, descriptions, illustrations, and general comments on the species are presented.

Additional key words: aquatic plants, Brazil, floristics, Nymphaea, taxonomy.
\end{abstract}

\section{NyMPhaEACEAE}

Ervas aquáticas, tuberosas; caule com feixes vasculares dispersos, canais de ar conspícuos, geralmente com esclereídes livres, estrelados, ramificados, que se projetam para dentro dos canais de ar. Folhas alternas, espiraladas, com ou sem estípulas, simples, flutuantes, lâmina peltada, cordada ou sagitada. Flores com pedúnculo longo, solitárias, grandes, vistosas, actinomorfas, bissexuadas, geralmente flutuantes; cálice dialissépalo, sépalas 4-6(-12), às vezes petaloides; corola dialipétala, pétalas 8 ou mais, dispostas espiraladamente; estames numerosos, anteras rimosas, filetes livres ou adnatos aos estaminódios petaloides; grãos de pólen geralmente monossulcados ou inaperturados; gineceu apocárpico ou sincárpico; ovário súpero a ínfero, multicarpelar, sincárpico, multilocular, placentação laminar, multiovulado. Fruto baga, esférico, desenvolvendo-se abaixo da superfície da água. Sementes frequentemente ariladas, com ou sem endosperma, perisperma presente.

Nymphaeaceae está incluída na ordem Nymphaeales, que representa um dos primeiros ramos divergentes das angiospermas (APG III 2009). A família possui distribuição cosmopolita, ocorrendo em ecossistemas de água doce com pouca ou nenhuma corrente. Inclui seis gêneros e cerca de 70 espécies (Bosch et al. 2008). No Brasil, ocorrem Nymphaea L. e Victoria Lindl., porém o número de espécies pode divergir bastante de acordo com os autores. Caspary (1878) reconheceu 10 espécies para o Brasil. Souza \& Lorenzi (2008) também reconheceram cerca de 10 espécies para o país, ao passo que Amaral (2010) reconheceu 19, sendo 18 de Nymphaea e uma de Victoria. Wiersema (1987), ao fazer a revisão de Nymphaea subg. Hydrocallis

*Autora para correspondência: carlabotanica@yahoo.com.br

Editor responsável: Pedro Fiaschi

Submetido em: 20 jun. 2011; publicação eletrônica: 11 jun. 2012
Planch., reconheceu 14 espécies, das quais 12 ocorrem no Brasil. Para a Região Nordeste, Barbosa et al. (2006) reconheceram 10 espécies, enquanto França (2006) citou apenas de Nymphaea amazonum Mart. \& Zucc. e N. ampla (Salisb.) DC. para o Semiárido. No presente trabalho, foram reconhecidas, descritas e ilustradas seis espécies de Nymphaeaceae, todas do gênero Nymphaea.

\section{Nymphaea L.}

Ervas perenes, enraizadas no substrato. Tubérculo ereto ou horizontal, ovoide a cilíndrico, com ou sem brotos gemíferos. Folhas com pecíolo longo, glabro ou pubescente, lâmina emergente ou flutuante, elípticosagitada a orbicular, margem inteira ou denteada, ápice arredondado a truncado, base cordada ou sagitada, geralmente peltada. Flores solitárias, flutuantes ou emergentes, diurnas ou noturnas, odoríferas, monoclinas, actinomorfas; sépalas (3)4(-6), livres, pétalas 40-70, livres, alvas, azuis, vermelhas ou amarelas, em transição abrupta ou gradual aos estames; estames numerosos, filetes dos estames externos mais largos, os internos filiformes, com ou sem prolongamentos terminais, anteras introrsas, bitecas e rimosas. Carpelos numerosos (5-47), pós-genitalmente sincárpicos ou apocárpicos e sem cômpito interno; estilete não distinto, cômpito extraginoecial pela presença de secreção; óvulos numerosos, anátropos. Fruto baga. Sementes com arilo membranoso flutuante, embrião pequeno, reto, endosperma reduzido, perisperma abundante. Pseudanto-tuberculíferos presentes ou não.

Conard (1905) dividiu o gênero Nymphaea em cinco subgêneros: Anecphya Casp. e Brachyceras Casp., com gineceu apocárpico, e Hydrocallis Planch., Lotus (L.) Willd. e Nymphaea, com gineceu sincárpico. Destes, apenas Nymphaea subgen. Brachyceras, com antese diurna, e $N$. subgen. Hydrocallis, com antese noturna (Conard 1905, Wiersema 1987), ocorrem na Bahia (para fotos, veja Figura 1). 


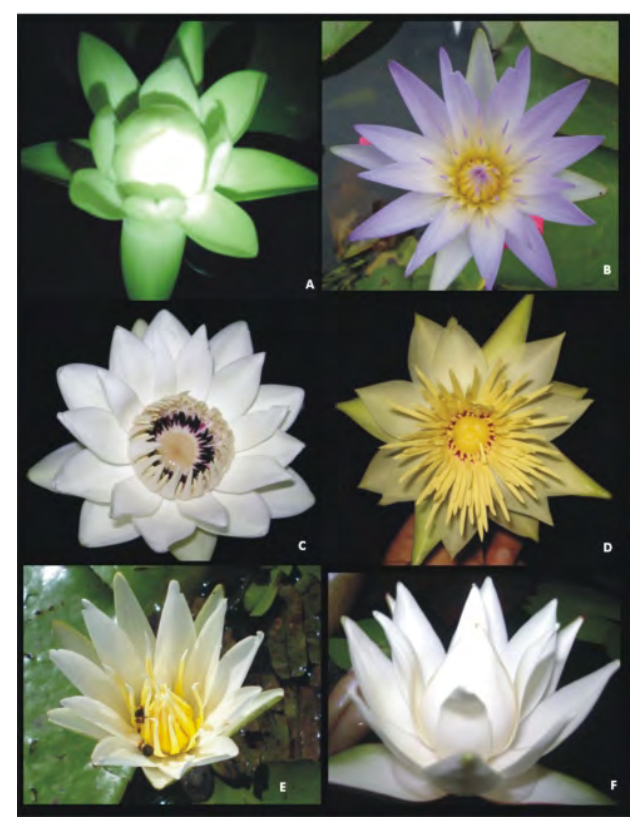

Figura 1. Flores de Nymphaea da Bahia: A-N. amazonum; B-N. caerulea; C-N. lasiophylla; D-N. lingulata $; \mathbf{E}-N$. pulchella; F-N. rudgeana.

\section{Chave de identificação}

1. Folhas com anel de tricomas no ápice do pecíolo 1.N. amazonum

1 '. Folhas sem anel de tricomas no ápice do pecíolo.

2. Folhas com margem irregularmente denteada; flores com transição gradual de pétalas para estames 6. N. rudgeana

2'. Folhas com margem inteira a denteada; flores com transição abrupta de pétalas para estames.

3. Prolongamento terminal dos estames $8,5-10 \mathrm{~mm}$ compr., apêndices carpelares triangulares.

4. Lâmina foliar cartácea, margem crenada a denteada; flores com pétalas e prolongamento terminal dos estames alvos; sementes com tricomas híspidos 5.N. pulchella

4'. Lâmina foliar coriácea, margem inteira a repanda; flores com pétalas e prolongamento terminal dos estames lilás; sementes glabras 2.N. caerulea

3'. Prolongamento terminal dos estames 2-4 $\mathrm{mm}$ compr., apêndices carpelares lingulados.

5. Lâmina foliar orbicular; flores com 16-21 ou 26 pétalas, apêndices carpelares vináceos, com ápice arredondado ................ 3. N. lasiophylla

5'. Lâmina foliar ovada; flores com 10-12 pétalas, apêndices carpelares alvo-amarelados, com ápice obtuso 4. N. lingulata

1. Nymphaea amazonum Mart. \& Zucc., Abh. Math.-Phys. Cl. Königl. Bayer. Akad. Wiss. 1: 363. 1832.

Figuras 1A, 2 e 3.

Tubérculo ovoide a subgloboso, sem brotos gemíferos. Folhas com pecíolo avermelhado, glabrescente, com anel de tricomas no ápice, 5-7,2 $\mathrm{mm}$ diâm., canais de ar 4 maiores centrais e 4 menores periféricos; lâmina coriácea, orbicular, ápice obtuso ou arredondado, margem inteira, face adaxial verde algumas vezes com manchas vermelhas por toda a lâmina, face abaxial vermelha, com nervura central proeminente, nervuras principais levemente proeminentes, $13-26 \times 12,6-18,5 \mathrm{~cm}$. Flores com pedúnculo avermelhado, 8,4-9 mm diâm., canais de ar 6 maiores centrais e 12 menores periféricos; sépalas 4; verdes, às vezes com manchas avermelhadas, 3,5-4,7 $\times$ 1,5-2,1 cm, oblongas, ápice agudo a arredondado, nervuras não evidentes; pétalas 16 ou 20, alvas, as mais externas 4-4,4 × 1,4-1,7 cm, as mais internas 3,4-3,8 × 1,3-1,5 cm, transição gradual para estames; oblongas, ápice arredondado, nervuras evidentes; estames 89-156, os mais externos 3,2-3,6 × 1,3-1,5 cm, os mais internos $1-1,3 \times$ 0,9-1 cm; filetes alvos; prolongamentos terminais alvos a creme, os mais externos 0,5-3 mm compr., os mais internos ausentes; anteras alvas a creme, as mais internas 7-9 mm compr.; carpelos 24-27, apêndices carpelares 6-8 × 2,7-3,2 $\mathrm{mm}$, alvos a creme, claviformes, ápice clavado rosa. Fruto geralmente presente, $2,6-3 \times 3,2-3,5 \mathrm{~cm}$. Sementes ovais, $1-1,3 \times 0,5-0,8 \mathrm{~mm}$, com linhas verticais de manchas acastanhadas, testa lisa, com tricomas pilosos em fileiras longitudinais. Pseudanto-tuberculífero raro, submerso, pedúnculo ca. $4 \mathrm{~mm}$ diâm., sepaloides externos 3, verdes, petaloides internos ausentes.

Espécie com distribuição neotropical, ocorre no México, América Central, Ilhas do Caribe e na América do Sul. No Brasil, ocorre nas Regiões Norte, Nordeste, CentroOeste e Sudeste (Feres \& Amaral 2003; Amaral 2010). Na Bahia, ocorre apenas $N$. amazonum subsp. amazonum, enquanto $N$. amazonum subsp. pedersenii Wiersema é restrita ao Pantanal do Mato Grosso (Wiersema 1987). D10, E9, E10: Mata Atlântica e formações sobre restinga. Floresce o ano todo.

Material selecionado - Cambuí, rodovia BA-99, km 125, 1203'12"S, 3742'57'W, 20 set. 2009 (fl., fr.), C. Lima et al. 248 (HUEFS); Candeias, BR-324, 12³8'45”S, 38'28'32”W, 12 jun. 2010 (fl., fr.), C. Lima et al. 366 (HUEFS); Conceição de Feira, rodovia BA-502, 12²5'40”'S, 38 57'45”'W, 22 maio 2010 (fl., fr.), C. Lima et al. 348 (HUEFS); Conde, Rio Cramaí, 1203'12"S, 37'42'57'W, 22 nov. 2009 (bot., fl., fr.), C. Lima et al. 308 (HUEFS); Entre Rios, rodovia BR-101, 12²2'34'S, 37³3'30"W, 22 nov. 2009 (bot., fl., fr.), C. Lima et al. 299 (HUEFS); Mata de São João, 12³1'S, $38^{\circ} 17^{\prime}$ W, 30 ago. 2009 (fl., fr.), C. Lima et al. 216 (HUEFS); Salvador, Parque de Pituaçu, 1257'S, 38²5'W, 25 jul. 2010 (fl., fr.), C. Lima et al. 375 (HUEFS); Santo Amaro, rodovia BA-324, Km 587, $12^{\circ} 69^{\prime} \mathrm{S}$, $38^{\circ} 28^{\prime} \mathrm{W}, 25$ jul. 2010 (bot., fl.), C. Lima et al. 372 (HUEFS).

Nymphaea amazonum é facilmente identificada pela presença de um anel de tricomas no ápice do pecíolo. A espécie tem flores monoclinas, com antese por volta das 18:00 horas, se fechando às 5:00 horas do dia seguinte. Cada flor abre por duas noites consecutivas. Na primeira noite, permanece aberta das 3:30 às 5:00 horas da manhã, liberando leve aroma de acetona. As flores são protogínicas, com referido por Prance (1980). Pseudanto-tuberculífero foi visto uma única vez, em material cultivado. Na Bahia, os espécimes foram coletados principalmente em águas paradas, às vezes um pouco salobra. 


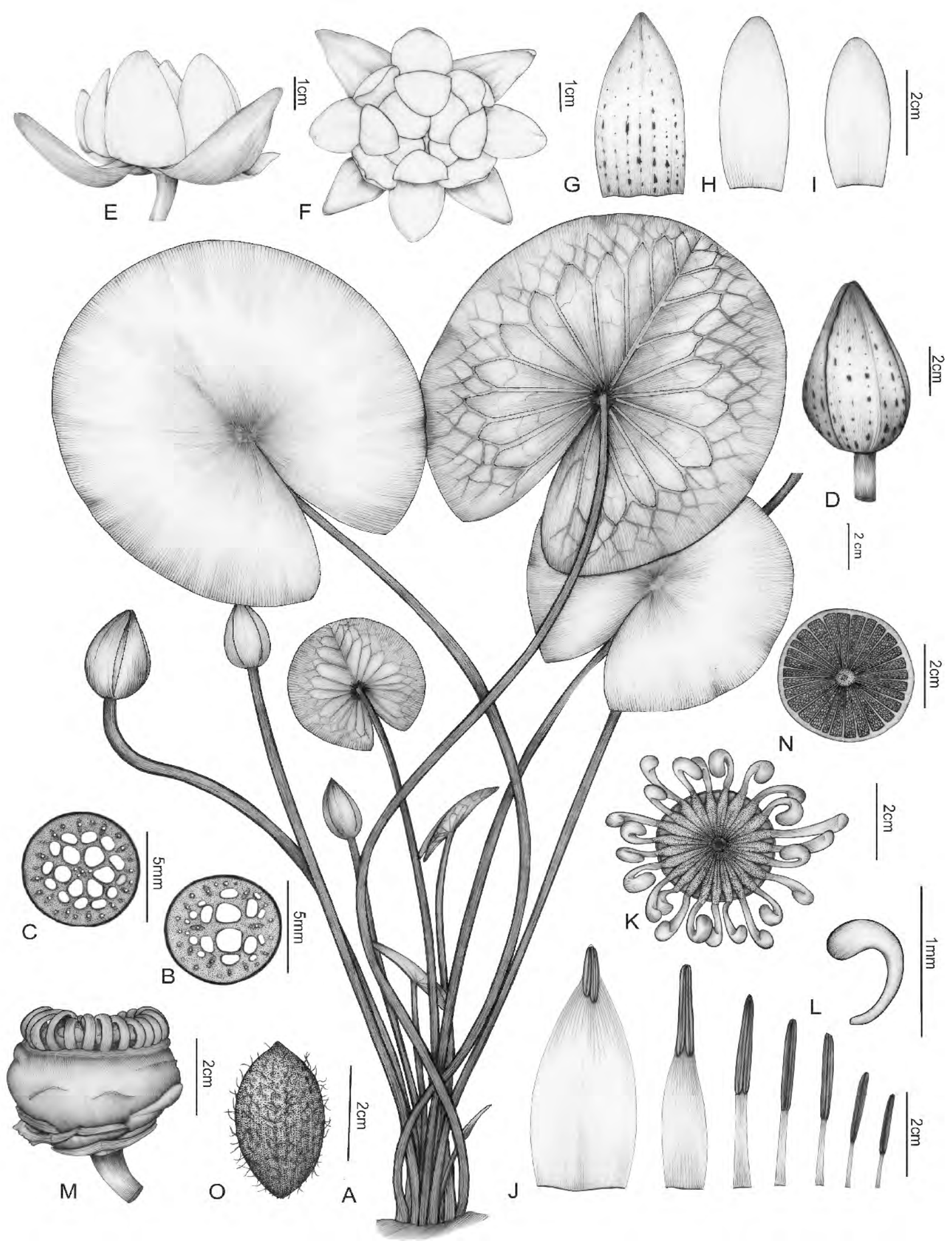

Figura 2. Nymphaea amazonum (Lima 248): A- hábito; B- corte transversal do pecíolo; C- corte transversal do pedúnculo; D- flor fechada; E- flor aberta, vista lateral; F- flor aberta, vista frontal; G- sépala; H- pétala maior; I- pétala menor; J- sequência de estames; K- gineceu, vista frontal; L- apêndice carpelar; $\mathbf{M}$ - fruto; $\mathbf{N}$ - corte transversal do fruto; $\mathbf{O}$ - semente. 


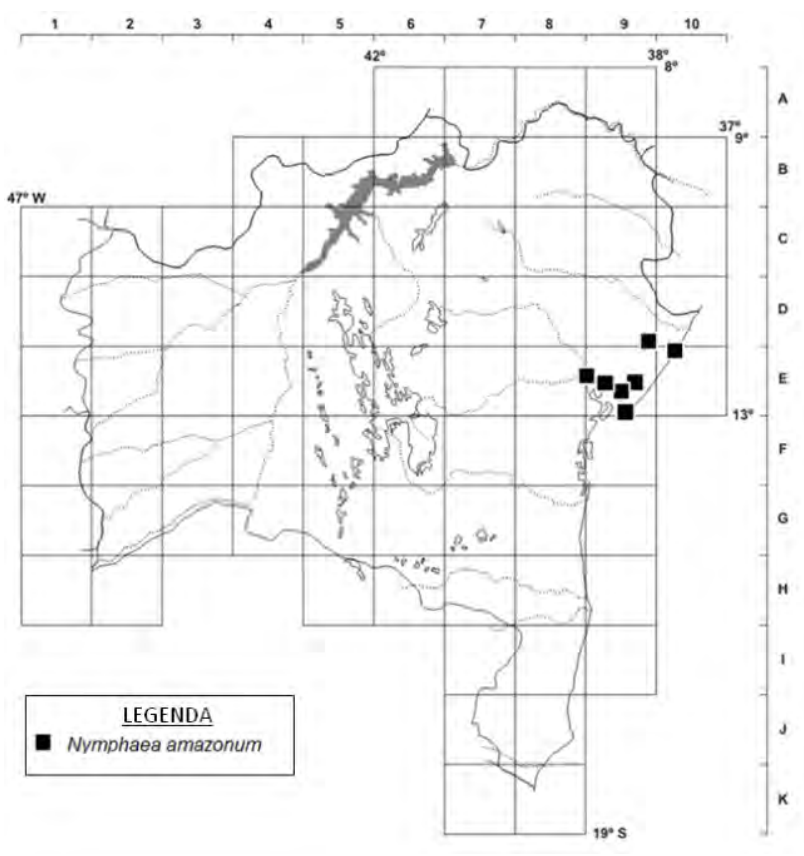

Figura 3. Pontos de coletas de Nymphaea amazonum na Bahia.

2. Nymphaea caerulea Savigny, Ann. Mus. Natl. Hist. Nat. 1:36. 1802.

Figuras 1B, 4 e 5.

Tubérculo ovoide a subgloboso, sem brotos gemíferos. Folhas com pecíolo avermelhado, glabrescente, sem anel de tricomas no ápice, 4,2-8,4 mm diâm., canais de ar 2 maiores centrais e 2 menores periféricos; lâmina coriácea, orbicular, ápice obtuso ou arredondado, margem inteira a repanda, face adaxial verde, algumas vezes com manchas vermelhas por toda a lâmina, face abaxial verde-clara, com margem avermelhada, com nervura central proeminente, nervuras principais levemente proeminentes, $25-33 \times$ 21,5-26 cm. Flores com pedúnculo avermelhado, 8,4-9,2 mm diâm., canais de ar 6 maiores centrais e 13 menores periféricos; sépalas 4; verdes com manchas avermelhadas, 5-8,7 × 2,4-3,2 cm, deltoide, ápice agudo a arredondado, nervuras evidentes; pétalas 14 ou 16, lilás, as mais externas lineares, $5,2-8 \times 1,6-1,8 \mathrm{~cm}$, as mais internas oblanceoladas, 3,6-7 × 0,8-1,3 cm; transição abrupta para estames; ápice agudo a acuminado, nervuras evidentes; estames 59-71, os mais externos 3,8-4,5 × 0,6-0,8 cm, os mais internos 1,3-1,7 $\times 0,3-0,6 \mathrm{~cm}$; filetes amarelos; prolongamentos terminais lilás, os mais externos ca. $1 \mathrm{~cm}$ compr., os mais internos $0,5-2 \mathrm{~mm}$ compr.; anteras amarelas, as mais internas $0,8-1 \mathrm{~cm}$ compr.; carpelos $19 \mathrm{ou}$ 20, apêndices carpelares 3-3,2 × 2,4-2,5 mm, amarelos, triangulares, ápice acuminado. Fruto geralmente presente, $3-3,3 \times 4-4,3 \mathrm{~cm}$. Sementes obovais, $1,1-1,4 \times 0,5-0,7$ $\mathrm{mm}$, com linhas sem manchas, testa estriada, glabras. Pseudanto-tuberculífero ausente.

Espécie africana (Hoehne 1948). No Brasil, têm ocorrência espontânea nas regiões Sudeste e Sul (Feres \& Amaral 2003; Amaral 2010). Esta é a primeira citação de ocorrência de $N$. caerulea no Nordeste. D7, F8, I8, J8: Mata Atlântica, formações sobre restinga e cerrado. Floresce todo o ano.
Material selecionado - Camamu, rodovia BR-101, $13^{\circ} 58^{\prime} 45^{\prime}$ 'S, 3909'35"W, 1 maio 2010 (bot., fl.), C. Lima et al. 337 (HUEFS); Eunápolis, rodovia BR-101, 16²16’38'S, 39³4'55'W, 1 maio 2010 (bot., fl.), C. Lima et al. 334 (HUEFS); Piritiba, estrada para Morro do Chapéu, fazenda Guanabara,

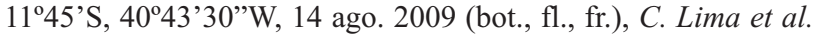
191 (HUEFS); Teixeira de Freitas, rodovia BR-101, 17²4'32'S, 3940'29"W, 30 abr. 2010 (bot., fl.), C. Lima et al. 333 (HUEFS).

Nymphaea caerulea pode ser identificada pela cor lilás das flores e dos prolongamentos dos estames, que são os mais longos dentre as Nymphaea da Bahia. Nesta espécie, as flores possuem antese diurna, apresentando-se abertas a partir das 8:00 horas da manhã e fechadas após às 14:00 horas. Cada flor abre por três a quatro dias consecutivos, liberando um aroma adocicado. Coletas com frutos inteiros são raras, pois eles são predados por animais aquáticos como peixes ou patos. Muitas flores observadas estavam sendo visitadas por Apis mellifera L., 1758, ou por Trigona spinipes Fabricius, 1793.

3. Nymphaea lasiophylla Mart. \& Zucc. Abh. Math. Phys. Cl. Königl. Beyer. Akad. Wiss. 1: 364. 1832. Figuras 1C, 6 e 7.

Tubérculo subgloboso, com brotos gemíferos. Folhas com pecíolo avermelhado, glabrescente, sem anel de tricomas no ápice, 2,3-7,2 mm diâm., canais de ar 2 maiores centrais e 6 menores periféricos; lâmina subcoriácea, orbicular, ápice arredondado, margem inteira, face adaxial verde, raro manchas vermelhas pela lâmina, face abaxial verde-amarronzada, com nervura central proeminente, nervuras principais não proeminentes, $14-30,3 \times 11,3-27,8$ $\mathrm{cm}$. Flores com pedúnculo verde-avermelhado, 5,9-8,2 mm diâm., canais de ar 6 maiores centrais e 12 menores periféricos; sépalas 4; verdes com base esbranquiçada, 5,6-8,3 × 2,5-3 cm, elípticas, ápice obtuso a agudo, nervuras não evidentes; pétalas $16-18$ ou 26 , alvas, as mais externas obovadas, 4,8-8,5 × 2-3,1 cm, as mais internas oblanceoladas, 5,3-5,7 × 0,8-1 cm; transição abrupta para estames; ápice arredondado, nervuras não evidentes; estames 72-165, os mais externos 2,7-4 × 0,6-0,9 cm, os mais internos $1,5-1,8 \times 0,15-0,2 \mathrm{~cm}$; filetes alvos, os mais internos rosa; prolongamentos terminais alvo-amarelados, os mais externos 2-3,5 mm compr., os mais internos 0,5-1,7 mm compr.; anteras alvo-amareladas, as mais internas 0,9-1,2 cm compr.; carpelos 19-23, apêndices carpelares 5,3-7,4 × 2,5-2,9 mm, vináceos, lingulados, ápice arredondado. Fruto raramente presente, 3-3,4 $\times$ 2,5-2,9 cm. Sementes ovais, 1-2,2 × 0,7-1 mm, com linhas sem manchas, testa lisa, tricomas pilosos em fileiras longitudinais. Pseudanto-tuberculífero sempre presente, emerso e submerso, pedúnculo 5-7 mm diâm., sepaloides externos 3 ou 4, verdes, petaloides internos até 4, verdeamarelados.

Distribuída do Rio de Janeiro ao norte do Piauí, com uma população disjunta, provavelmente introduzida, na Ilha de Margarita, Venezuela (Wiersema 1987). De acordo com Amaral (2010), N. lasiophylla ocorre nas Regiões Nordeste e Sudeste. C7, C8, D6, D8, D7, E7: no norte do estado, em regiões semiáridas, com vegetação típica de caatinga e em restinga. Floresce o ano todo. 


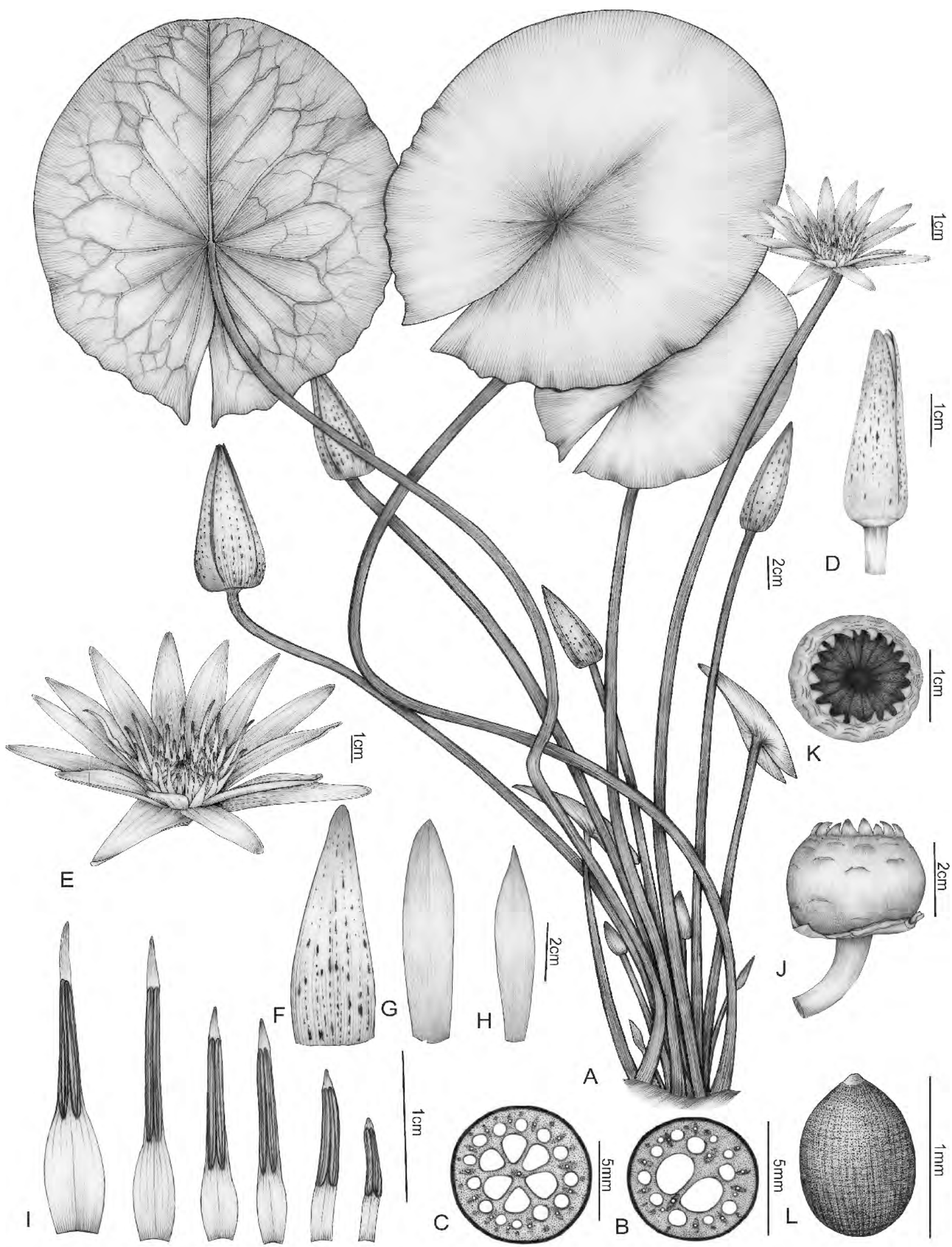

Figura 4. Nymphaea caerulea (Lima 191): A- hábito; B- corte transversal do pecíolo; C- corte transversal do pedúnculo; D- flor fechada; E- flor aberta; Fsépala; G- pétala maior; H- pétala menor; I- sequência de estames; J- fruto, vista lateral; K- fruto, vista frontal; L- semente. 


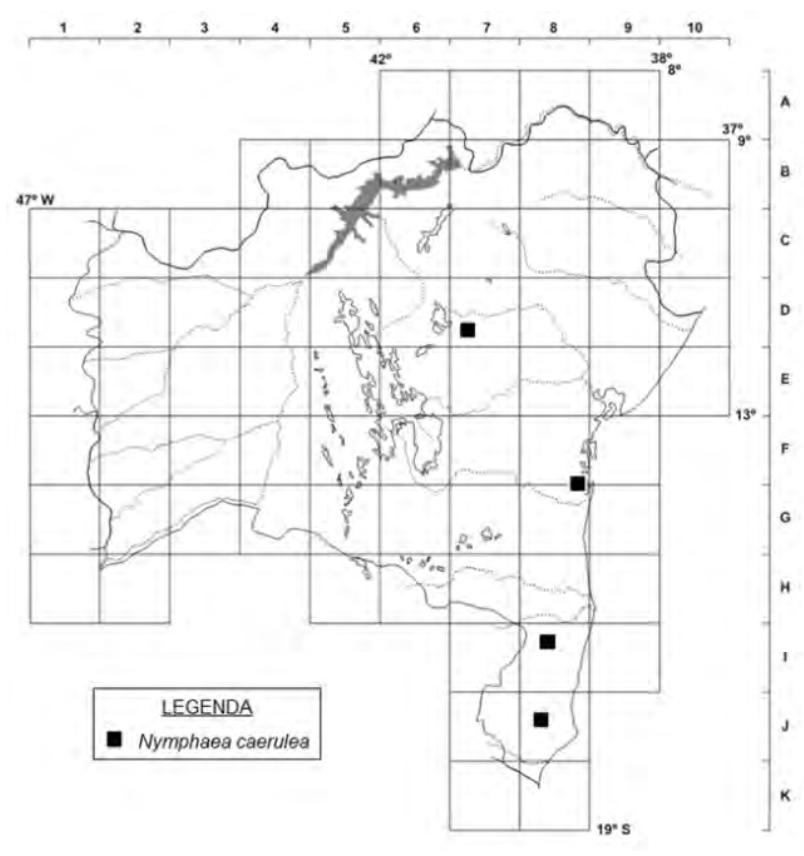

Figura 5. Pontos de coleta de Nymphaea caerulea na Bahia.

Material selecionado - Capim Grosso, fazenda Ribeiro, estrada vicinal entre o Distrito de Pereira e o município de Capim Grosso, 11²0'45”S, 3957'48”'W, 5 ago. 2009 (bot., fl., fr.), C. Lima et al. 224 (HUEFS); Conde, rio Cramaí, 1246’30"S, 37³6'00'W, 20 set. 2009 (est.), C. Lima et al. 250 (HUEFS); Feira de Santana, Lagoa da Pindoba, $11^{\circ} 41^{\prime} 28^{\prime}$ "S, 41 01 '28"'W, 250 m, 30 maio 2005 (fl.), F. França et al. 5239 (CEPEC, HRB, HUEFS); Feira de Santana, rodovia BR-116, Km 8, margem do rio Jacuípe, 19 fev. 1981 (est.), A.M. Carvalho et al. 593 (CEPEC); Filadélfia, lagoa próximo ao Povoado de Carrapato, 1042'46”S, 4002'16”W, 6 set. 2009 (est.), C. Lima et al. 232 (HUEFS); Itaberaba, estrada para Ipirá, a $5 \mathrm{~km}$ da cidade, $12^{\circ} 29^{\prime} 20^{\prime \prime} \mathrm{S}$, 40¹3'36”'W, 13 dez. 2009 (fl.), C. Lima et al. 326 (HUEFS); Itiúba, estrada sentido açude de Comandaroba, fazenda Vivera, 10³9'30'S, 3952'36”'W, 6 set. 2009 (bot., fl., fr.), C. Lima et al. 230 (HUEFS); Jacobina, estrada sentido Miguel Calmon, 11'11'15"S, 40³4'09'W, 6 set. 2009 (est.), C. Lima et al. 233 (HUEFS); Miguel Calmon, ponte na divisa com Piritiba, $11^{\circ} 19^{\prime} 41^{\prime \prime}$ S, 40³6'30"W, 11 out. 2009 (est.), C. Lima et al. 265 (HUEFS); São Félix, rio Paraguaçu, embaixo da ponte entre São Félix e Cachoeira, 12³5'34'S, 3859'17'W, 22 maio 2010 (est.), C. Lima et al. 349 (HUEFS); Senhor do Bonfim, povoado Lagoa do Peixe, 10²5'27'S, 40¹0'14'W, 5 ago. 2009 (est.), C. Lima et al. 227 (HUEFS).

Nymphaea lasiophylla possui flores com antese noturna. A abertura ocorre por volta das 18:00 horas e o fechamento se dá em torno das 2:00 horas do dia seguinte. Cada flor abre por duas noites consecutivas, liberando forte aroma de acetona. Todos os espécimes coletados apresentaram pseudanto-tuberculíferos, reforçando a posição de Wiersema (1987) de que N. lasiophylla possui reprodução geralmente assexuada.

4. Nymphaea lingulata Wiersema, Brittonia 36: 215. 1984. Figuras 1D, 8 e 9.

Tubérculo ovoide a subgloboso, com brotos gemíferos. Folhas com pecíolo amarronzado, glabrescente, sem anel de tricomas no ápice, 3,3-7,4 mm diâm., canais de ar 4 maiores centrais e 10 menores periféricos; lâmina coriácea, oval, ápice arredondado, margem inteira, face adaxial verde, face abaxial vermelha, com nervura central levemente proeminente, nervuras principais não proeminentes, 12,5-23,8 $\times 11,2-17,3 \mathrm{~cm}$. Flores com pedúnculo avermelhado, 4-6 mm diâm., canais de ar 5 maiores centrais e 10 menores periféricos; sépalas 4, verdeesbranquiçadas, 4-9,8 × 2,4-3,3 cm, elípticas, ápice agudo, nervuras não evidentes; pétalas 10-12, alvas, as mais externas elípticas, 8,5-9,7 × 3,6-4,5 cm, as mais internas oblanceoladas, 5,3-5,7 × 2,2-2,5 cm; transição abrupta para estames; ápice acuminado, nervuras não evidentes; estames 102-123, os mais externos 2,8-3 × 0,2-0,3 cm, os mais internos 2-3 $\times 0,1-0,2 \mathrm{~cm}$; filetes alvos, os mais internos rosas; prolongamentos terminais alvo-amarelados, os mais externos 4-5 mm compr., os mais internos 0,5-3 $\mathrm{mm}$ compr.; anteras alvo-amareladas, as mais internas $2-2,3 \mathrm{~cm}$ compr.; carpelos 20-25, apêndices carpelares 10-12 × 2,2-2,5 mm, alvo-amarelados, lingulados, ápice obtuso. Fruto presente, 1,5-2 $\times 2,7-3 \mathrm{~cm}$. Sementes ovais, 0,8-1,1 x $0,5-0,8 \mathrm{~mm}$, sem manchas, testa levemente estriada, tricomas incanos em fileiras longitudinais. Pseudantotuberculífero raro, submerso, pedúnculo 7-8 mm diâm., sepaloides externos 4, verdes, petaloides internos ausentes.

Espécie distribuída nas Regiões Nordeste, Sudeste e Centro-Oeste do Brasil (Wiersema 1987; Amaral 2010). Este é o primeiro registro de $N$. lingulata no estado da Bahia. D7, E6, E9: floresta semidecidual, caatinga e restinga. Floresce o ano todo.

Material selecionado - Andaraí, Pantanal de Marimbus,

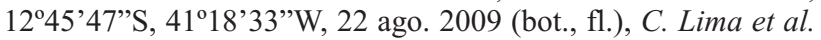
213 (HUEFS); Muritiba, represa da fazenda Capivari, 12³8'26"S, 3904'23”'W, 22 mar. 2009 (fl.), L.Y.S. Aona et al.

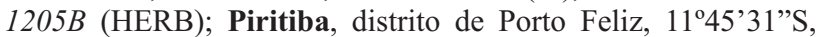

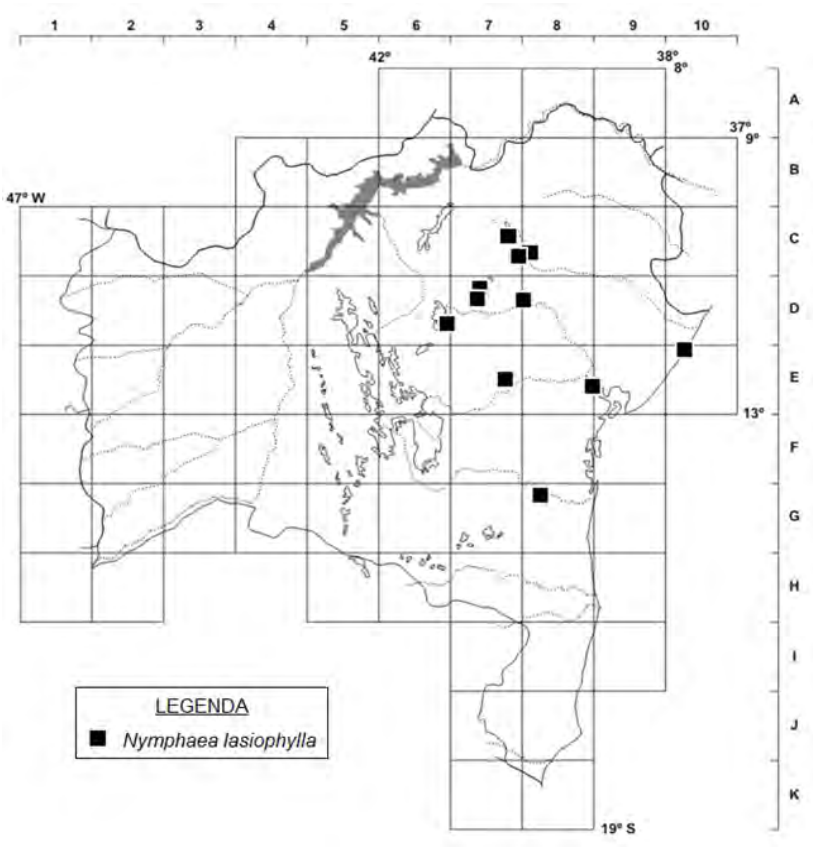

Figura 6. Pontos de coleta de Nymphaea lasiophylla na Bahia. 


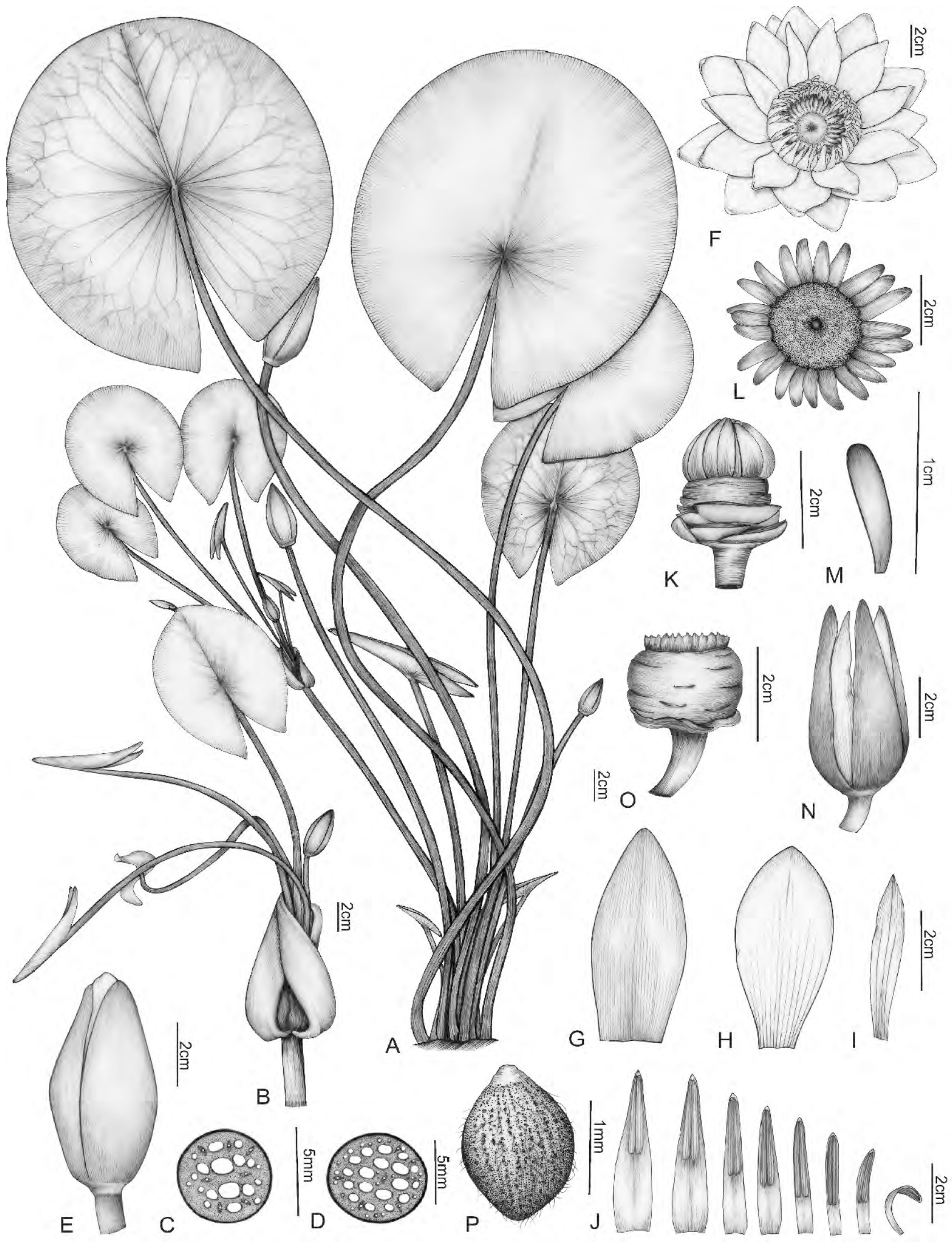

Figura 7. Nymphaea lasiophylla (Lima 230): A- hábito; B-pseudanto-tuberculífero; C- corte transversal do pecíolo; D- corte transversal do pedúnculo; Eflor fechada; F- flor aberta; G- sépala; H- pétala maior; I- pétala menor; J- sequência de estames; K- gineceu, vista lateral; L- gineceu, vista frontal; Mapêndice carpelar; $\mathbf{N}$ - fruto com perianto persistente; $\mathbf{O}$ - fruto, perianto removido, vista lateral; $\mathbf{P}$ - Semente. 


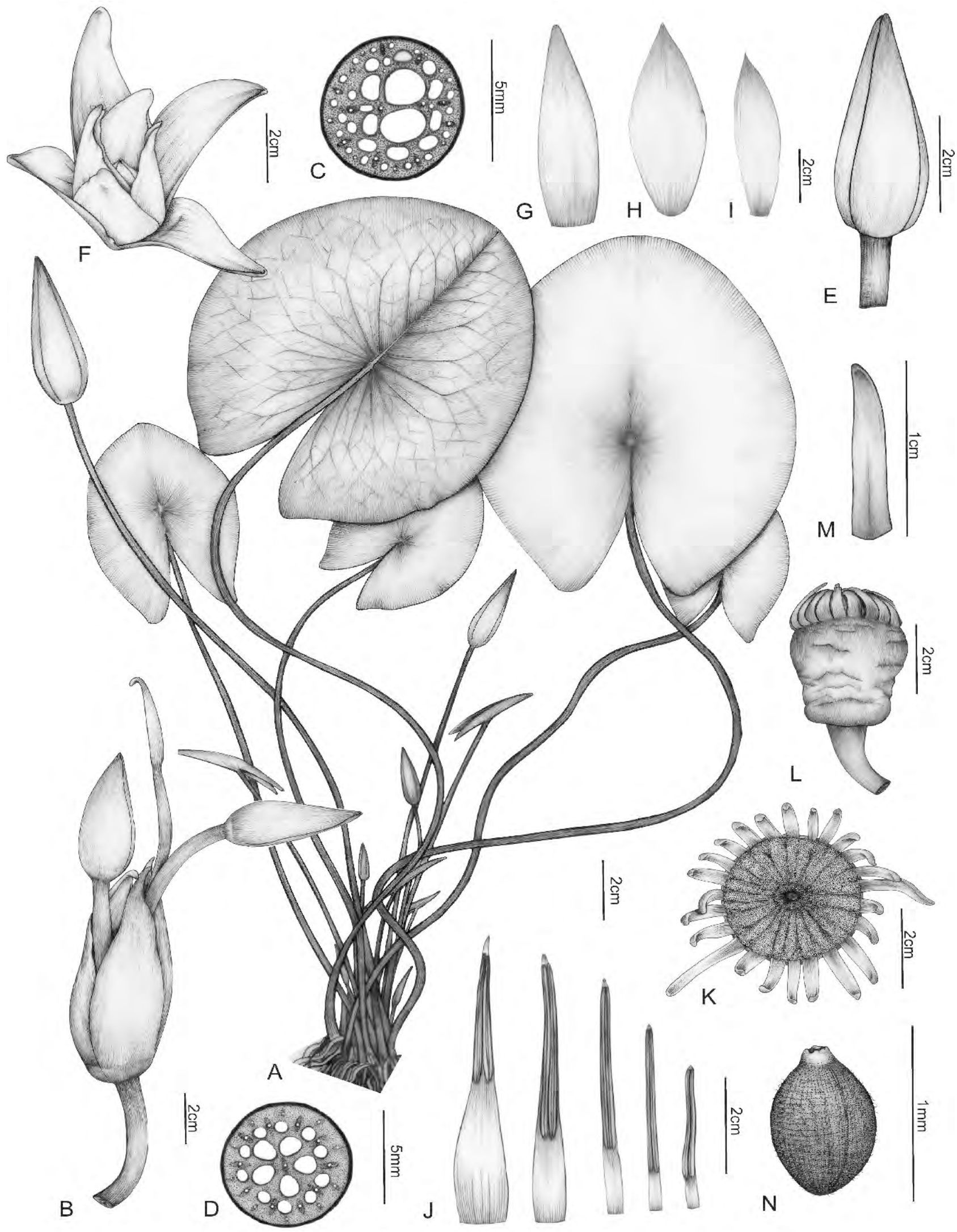

Figura 8. Nymphaea lingulata (Lima 241): A- hábito; B- pseudanto-tuberculífero; C- corte transversal do pecíolo; D- corte transversal do pedúnculo; Eflor fechada; F- flor aberta; G- sépala; H- pétala maior; I- pétala menor; J- sequência de estames; K- gineceu, vista frontal; L- gineceu, vista lateral; Mapêndice carpelar; $\mathbf{N}$-semente.

Sitientibus série Ciências Biológicas 12(1): 69-82. 2012. 


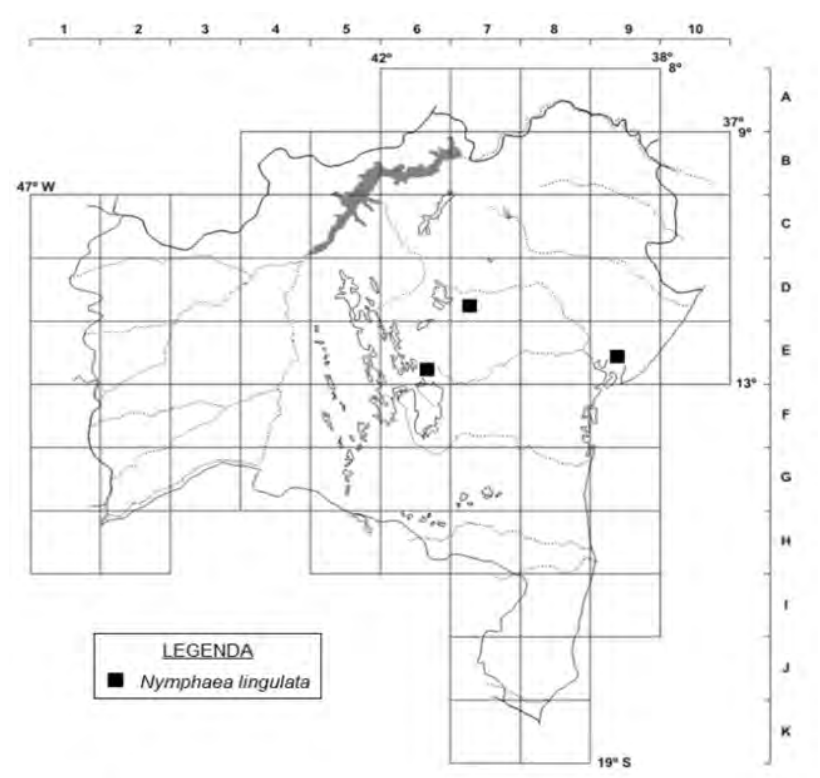

Figura 9. Pontos de coleta de Nymphaea lingulata na Bahia.

4042'29”'W, 15 ago. 2009 (est.), C. Lima et al. 208 (HUEFS); São Francisco do Conde, Praia do Conde, 12³4'S, 38 36'W, 26 dez. 2002 (est.), R.M. Harley etal. 54520 (HUEFS).

Nymphaea lingulata pode ser identificada por apresentar a lâmina foliar com a face abaxial fortemente avermelhada e com nervuras não proeminentes. Possui flores com antese noturna, com abertura por volta das 18:00 horas e fechamento por volta das 3:00 horas. Cada flor abre por duas noites consecutivas, liberando aroma de acetona. A presença de pseudanto-tuberculífero foi registrada pela primeira vez na espécie (Lima 2011).

\section{Nymphaea pulchella DC., Syst. Nat. 2: 51. 1821. Figuras 1E, 10 e 11.}

Tubérculo subgloboso a cilíndrico, sem brotos gemíferos. Folhas com pecíolo verde a avermelhado, glabrescente, sem anel de tricomas no ápice, 3,7-14,3 mm diâm., canais de ar 2 maiores centrais e 2 menores periféricos; lâmina cartácea, orbicular, ápice obtuso ou arredondado, margem crenada a denteada, face adaxial verde, face abaxial verde clara, geralmente com manchas vermelhas por toda a lâmina em ambas as faces, com nervura central fortemente proeminente, nervuras principais proeminentes, $20-45 \times 14,5-34 \mathrm{~cm}$. Flores com pedúnculo avermelhado, 4,6-11,4 mm diâm., canais de ar 6 maiores centrais e 13 menores periféricos; sépalas 4; verdes com manchas avermelhadas, 4,8-5,3 $\times 1,2-1,6 \mathrm{~cm}$, lanceoladas, ápice agudo a arredondado, nervuras evidentes; pétalas 11-13 ou 17, alvas, estreito-elípticas, as mais externas 5,6-8,9 × 1,5-2 cm, as mais internas 4,5-5,2 $\times 1-1,5 \mathrm{~cm}$; transição abrupta para estames; ápice agudo a acuminado, nervuras evidentes; estames 43-80, os mais externos 2,5-3 × 0,4-0,5 cm, os mais internos 6-8 $60,8-1$ $\mathrm{mm}$; filetes amarelos; prolongamentos terminais amarelos, os mais externos ca. 8,5 mm compr., os mais internos 1-1,3 $\mathrm{mm}$ compr.; anteras amarelas, as mais internas $3-4 \mathrm{~mm}$ compr.; carpelos 15-23, apêndices carpelares 4,8-5,1 $\times$ 3-3,5 mm, amarelos, triangulares, ápice acuminado. Fruto geralmente presente, $3-4,5 \times 4,5-6,5 \mathrm{~cm}$. Sementes obovais, 1,3-1,6 × 1-1,2 mm, com linhas sem manchas, testa lisa, tricomas híspidos em fileiras longitudinais. Pseudanto-tuberculífero ausente.

Espécie distribuída nos trópicos e subtrópicos das Américas, incluindo o México, países da América Central e norte da América do Sul (Wiersema 2008). De acordo com Amaral (2010), N. pulchella ocorre nos estados da Bahia e do Ceará. B6, C7, C8, C9, D7, D8, D9, E4, E6, E7, E8, E9, E10, G7, G8, H9: amplamente distribuída por todo o estado sendo comum em lagoas artificiais da região semiárida da Caatinga, no Cerrado, em campos rupestres e na Mata Atlântica, em florestas semideciduais e formações sobre restinga.

Material selecionado - Andaraí, Pantanal de Marimbus, $12^{\circ} 45^{\prime} 4^{\prime \prime S}, 41^{\circ} 18$ '33”'W, 22 ago. 2009 (bot., fl.), C. Lima et al. 212 (HUEFS); Anguera, fazenda Caraíba, rodovia BA-052, Km 17, $12^{\circ} 11^{\prime} 35^{\prime} \mathrm{S}, 39^{\circ} 09^{\prime} 03$ ”'W, $220 \mathrm{~m}, 29$ jun. 2003 (fl.), K.R.B. Leite et al. 363 (HUEFS); Antônio Gonçalves, estrada para Pindobaçu, 10 out. 2009 (bot., fl.), Lima et al. 260 (HUEFS); Belmonte, rodovia BR-101, Km 1, 17 abr. 1975 (fl.), T.S. Santos 2986 (CEPEC); Camaçari, estrada para o rio Barra do Jacuípe, 126' S, 38¹7'W, 30 ago. 2009 (bot., fl.), C. Lima et al. 218 (HUEFS); Candeias, rodovia BR-324, 12'38'45”S, 38²8'32”W, 12 jun. 2010 (bot., fl., fr), C. Lima et al. 367 (HUEFS); Capim

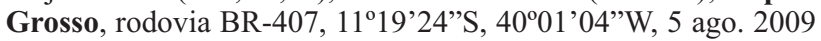
(bot., fl., fr), C. Lima et al. 226 (HUEFS); Conceição de Feira, rodovia BR-502, entre Conceição de Feira e São Gonçalo, $12^{\circ} 25^{\prime} 40^{\prime \prime S}, 38^{\circ} 57^{\prime} 45^{\prime \prime} \mathrm{W}, 22$ maio 2010 (bot., fl.), C. Lima et al. 347 (HUEFS); Conde, rio Cramaí, 1203'12”'S, 3742'57'W, 22 nov. 2009 (bot., fl.), C. Lima et al. 312 (HUEFS); Entre Rios, Rio

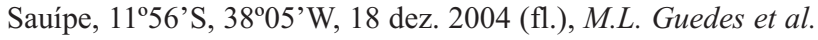
11404 (ALCB). Esplanada, Dunas de Baixio, 1206'25"S, 3741'51'W, 23 jun. 2004 (fl.), T. Jost et al. 667 (HRB); Euclides da Cunha, estrada sentido Monte Santo, 10³5'10"'S, 38 58'54"W, 9 out. 2009 (fl., fr), C. Lima et al. 254 (HUEFS); Feira de Santana, rodovia BA-52, 12 14 '36”'S, 3905'16”W, 19 jul. 2009 (bot., fl.), C. Lima et al. 165 (HUEFS); Floresta Azul, fazenda Boa Vista, distrito de Coquinho, 1 maio 1989 (fl.). H.S. Brito et al. 284 (CEPEC); Ipirá, rodovia BA-52, 19 jul. 2009 (bot., fl., fr), C. Lima et al. 175 (HUEFS); Itaberaba, rodovia BA-488, 12²9'20"S, 40¹3'36”'W, 19 jun. 2009 (bot., fl.), C. Lima et al. 164 (HUEFS). Itapé, 3 mar. 1971 (fl.), R.S. Pinheiro 1048 (CEPEC); Itagibá, Campo Verde, 14¹0'02”S, 3943'20”W, 15 set. 2008 (fl.), C.E. Gomes et al. 352 (ALCB); Itiúba, BA-381, 10³9'S, 3952'W, 6 set. 2009 (bot., fl.), C. Lima et al. 231 (HUEFS); Jacobina, lagoa Antônio Sobrinho, 11\%11'15'S, 40³3'24”W, 420 m, 2 nov. 1997 (bot., fl.), F. França et al. 2457 (CEPEC, HUEFS); Juazeiro, rio Salitre, rodovia BA-210, 09³3'43”'S, 40³9'20'"W, 10 out. 2009 (fl., fr), C. Lima et al. 258 (HUEFS); Lençóis, Marimbus de Remanso, 12 ${ }^{\circ} 39^{\prime} \mathrm{S}, 41^{\circ} 19^{\prime} \mathrm{W}$, 380 m, 29 jan. 1997 (fl.), M.L. Guedes et al. 4617 (ALCB); Mata de São João, rio Açu, $12^{\circ} 31^{\prime} \mathrm{S}, 38^{\circ} 17^{\prime} \mathrm{W}, 23$ maio 2000 (fl.), D.L. Santana 100 (ALCB); Miguel Calmon, ponte na divisa com Piritiba, 11\%19'41'S, 40³6'30"W, 11 out. 2009 (bot., fl.), C. Lima et al. 264 (HUEFS); Morro do Chapéu, estrada Lajedo Bordado, 30 maio 2010 (bot. fl., fr), C. Lima et al. 361 (HUEFS); Mundo Novo, rio Paraguaçu, Pedra do Cavalo, $11^{\circ} 51^{\prime}$ S, $40^{\circ} 28^{\prime} \mathrm{W}, 18$ jan. 2009 (fl.), F.S. Gomes et al. 159 (ALCB); Olindina, Riacho da Barra, 12³1'S, 952'W, 20 jul. 1993 (est.), O. Barreto 34 (RB); Palmeira, BR-422, 12²9'18'S, 4143'59'W, 13 dez. 2009 (bot., fl.), C. Lima et al. 325 (HUEFS); Pindobaçu, Ponte de divisa com Filadélfia, 1042'17'’, $40^{\circ} 15^{\prime} 40$ 'W, 6 set. 2009 (bot., fl.), C. Lima

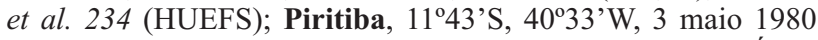
(est.), L.R. Noblick et al. 1873 (ALCB); Ruy Barbosa, rio Água 


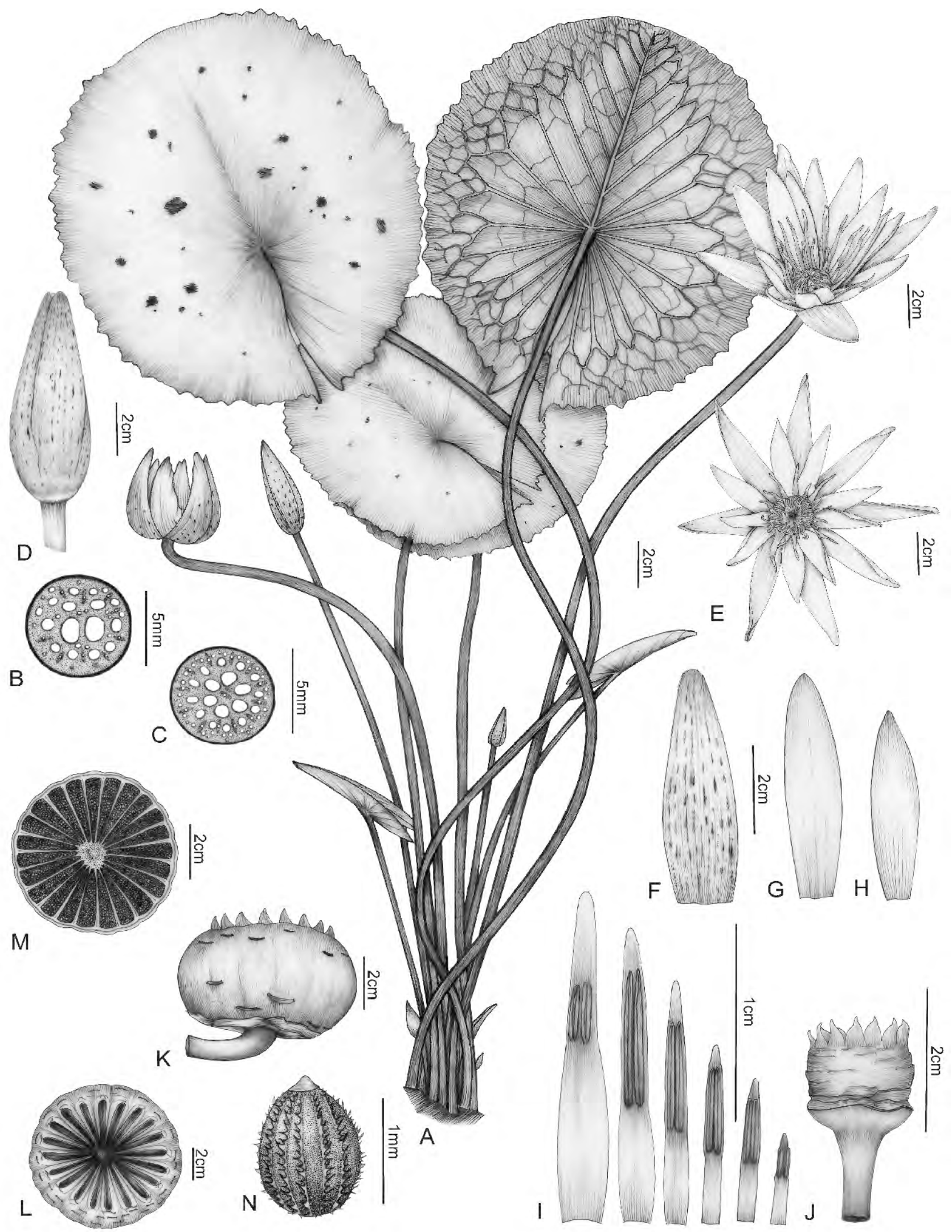

Figura 10. Nymphaea pulchella (Lima 231): A- hábito; B- corte transversal do pecíolo; C- corte transversal do pedúnculo; D- flor fechada; E- flor aberta; F-sépala; G- pétala maior; H- pétala menor; I- sequência de estames; J- gineceu; K- fruto, vista lateral; L- fruto, vista frontal; M-corte transversal do fruto. $\mathrm{N}$-semente.

Sitientibus série Ciências Biológicas 12(1): 69-82. 2012. 


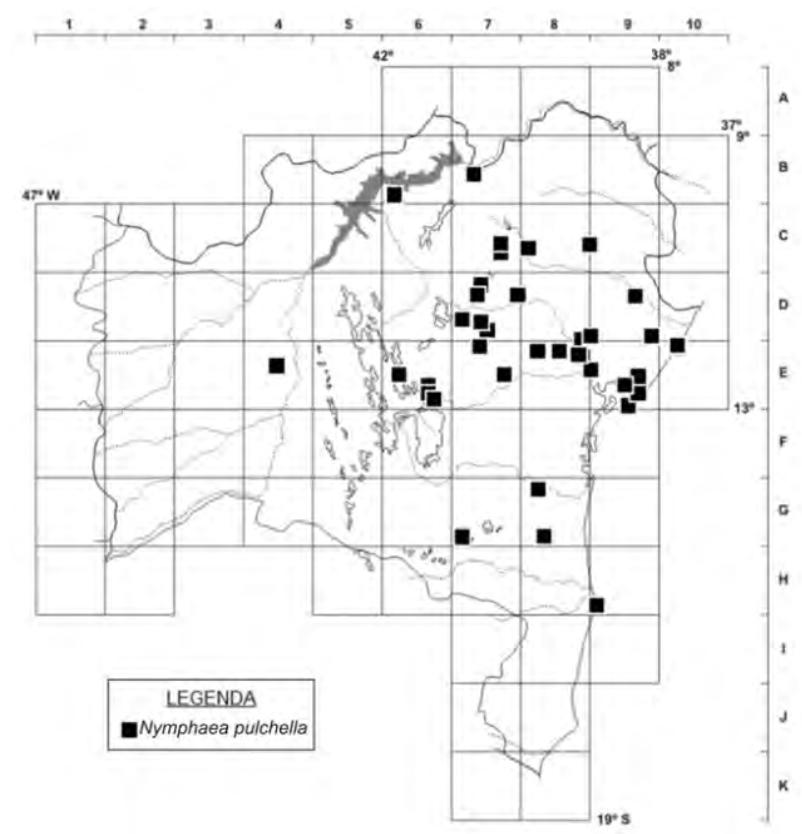

Figura 11. Pontos de coleta de Nymphaeae pulchella na Bahia.

Branca, 1205'07'S, 40³4'01'W, 19 maio 2001 (bot., fl.), M.L. Guedes et al. 9212 (ALCB); Salvador, Stella Mares, 1256'37'S, $38^{\circ} 25^{\prime} 42^{\prime}$ 'W, 12 nov. 2005 (fl.), E.P. Queiroz et al. 1271 (ALCB);

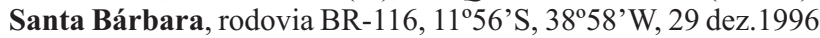
(fl.), R.M. Harley et al. 28467 (HUEFS); Seabra, próximo ao povoado Oliveira dos Brejinhos, 12²1'49"S, 4330'25"W, 12 dez. 2009 (bot., fl.), C. Lima et al. 323 (HUEFS); Sento Sé, Riacho do Brejo, 0952'22"S, 41\%48'27'W, 20 jul. 1993(fl.), J.A. Siqueira-Filho et al. 1657 (HVASF); Serra Preta, estrada para Bravo, 12'08'37'S, 39²4'34'W, 19 jul. 2009 (bot., fl.), C. Lima et al.168 (HUEFS); Tanquinho, rodovia BR-324, 11'58'53'S, 3905'31'W, 4 set. 2009 (bot., fl.), C. Lima et al. 219 (HUEFS); Vitória da Conquista, 26 jun. 1965 (est.), R.P. Belém 1232 (CEPEC); Wagner, fazenda Mariela, rio Utinga, $12^{\circ} 51$ 's, 41ํ1'W, 3 mar. 2003 (fl.), L.R. Senna 163 (HUEFS).

Nymphaea pulchella possui flores com antese diurna, apresentando-se abertas a partir das 8:00 horas da manhã e fechadas após as 17:00 horas. Cada flor abre por três a quatro dias consecutivos liberando aroma adocicado. Foi observada com flores visitadas por Apis mellifera e/ou Trigona spinipes.

Grande parte do material examinado dessa espécie nos herbários visitados estava sem identificação ou identificado como Nymphaea ampla. Este nome aparece em trabalhos anteriores realizados no estado da Bahia (França et al. 2003; França 2006). Wiersema (2008) fez uma análise comparativa entre $N$. ampla e $N$. pulchella e concluiu que elas diferem no número de estames [80-190(-222) em $N$. ampla e 30-90 em $N$. pulchella] e número de pétalas (13-28 em N. ampla e 4-23 em N. pulchella). Elas também possuem distribuições geográfica distintas; segundo o autor, N. ampla está restrita à America do Norte, enquanto $N$. pulchella ocorre nas Américas Central e do Sul e nas Antilhas. A distinção entre essas duas espécies ainda é um tema em discussão e precisa ser melhor investigada. Apesar de termos observado sobreposição em alguns dos caracteres diagnósticos indicados por Wiersema (2008) nos materiais da Bahia, eles se adéquam com mais propriedade a $N$. pulchella.

6. Nymphaea rudgeana G.Mey., Prim. Fl. Esseq.: 198. 1818.

Figuras 1F, 12 e 13 .

Tubérculo subgloboso a cilíndrico, sem brotos gemíferos. Folhas com pecíolo avermelhado, glabrescente, sem anel de tricomas no ápice, 4,9-8,3 mm diâm., canais de ar 2 maiores centrais e 10 menores periféricos; lâmina cartácea, largo-elíptica, ápice truncada a arredondado, margem denteada irregularmente com ápice repanda, face adaxial verde ou avermelhada, face abaxial verde ou vermelha, com nervura central e principais fortemente proeminente, $12-36 \times 10-38 \mathrm{~cm}$. Flores com pedúnculo avermelhado, 6,5-12,6 mm diâm., canais de ar 6 maiores centrais e 12 menores periféricos; sépalas 4; verdes ou rosadas, às vezes com manchas avermelhadas, 4,1-7,3 $\times$ 2,4-3,2 cm, elípticas, ápice agudo a arredondado, nervuras não evidentes; pétalas 12,16 ou 20, alvas a rosadas, as mais externas elípticas, 5,3-5,6 × 2,1-2,7 cm, as mais internas estreito-elípticas, 3,8-4,3 × 1,2-1,6 cm; transição gradual para estames; ápice arredondado, nervuras não evidentes; estames 50-89, os mais externos 3,6-4,1 × 1,1-1,3 cm, os mais internos $1,6-1,8 \times 0,3-0,4 \mathrm{~cm}$; filetes alvos; prolongamentos terminais alvo-amarelados, os mais externos 0,2-0,5 mm compr., os mais internos ausentes; anteras alvo-amareladas, as mais internas 1,5-1,8 cm compr.; carpelos 11-20, apêndices carpelares 9-13 $\times$ 1,5-2,2 mm, alvo-amarelados, claviformes, ápice clavado rosa. Fruto geralmente presente, 2,5-4 × 3,2-5,3 cm. Sementes ovais, 1,4-2 × 1-1,5 mm, sem manchas, testa lisa, com tricomas pilosos em fileiras longitudinais. Pseudanto-tuberculífero ausente.

Espécie distribuída nas Américas Central e do Sul e nas Ilhas do Caribe. No Brasil, é referida para as Regiões Norte, Nordeste, Sudeste e Sul (Amaral 2010). D9, E6, E7, E8, E9, E10, F6, F8, G8, H8, H9, I8, J8: floresta semidecidual, campos rupestres e formações sobre restinga. Floresce o ano todo.

Material selecionado - Andaraí, Pantanal de Marimbus, $12^{\circ} 45^{\prime} 47^{\prime}$ 'S, $41^{\circ} 18$ '33”W, 22 ago. 2009 (bot.), C. Lima et al. 211 (HUEFS); Cachoeira, Vale do Rio Paraguaçu, $12^{\circ} 32^{\prime} \mathrm{S}, 39^{\circ} 05^{\prime} \mathrm{W}$, ago. 1980 (bot.), Grupo Pedra do Cavalo 619 (ALCB, CEPEC, NY, RB); Cairu, Ilha do Morro de São Paulo, lagoa próximo a um hotel, 6 out. 1996 (fl.), R.M. Harley et al. 28441 (HUEFS);

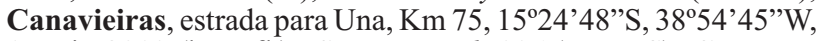
1 maio 2010 (bot., fl.), C. Lima et al. 336 (HUEFS); Cascavel, Lagoa Encantada, 1318'01'S, 4119'06"W, 21 mar. 1999 (fl.), R.M. Harley et al. 53565 (HUEFS); Conde, rio Cramaí, 12'46’30"S, 37³6'00”W, 20 set. 2009 (fl., fr), C. Lima et al. 251 (HUEFS); Dias Dávila, 12 dez. 1997 (est.),W.B. Augusto et al. 12 (ALCB); Eunápolis, rodovia BR-101, 16 ${ }^{\circ} 16^{\prime} 38^{\prime \prime S}, 39^{\circ} 34^{\prime} 55^{\prime \prime} \mathrm{W}$, 1 maio 2010 (fl.), C. Lima et al. 335 (HUEFS); Ilhéus, a $5 \mathrm{~km}$ de Olivença, 11 jan. 1996 (bot.), L.A. Mattos Silva et al. 3300 (ALCB, HUEFS, SPF); Lençóis, rio São José, a $2 \mathrm{~km}$ da cidade, $12^{\circ} 33$ '20"S, 40²2'54”'W, 23 ago. 2009 (bot., fl., fr), C. Lima et al. 215 (HUEFS); Mata de São João, foz do rio Santo Antônio, $12^{\circ} 31^{\prime}$ 'S, $38^{\circ} 17^{\prime}$ W, 17 maio 2000 (fl.), D.L. Santana 82 (ALCB, HRB); Mucugê, $13^{\circ} 00^{\prime} 00^{\prime}$ 'S, 41 22 '12"W, nov. 2010 (fl., fr), $C$. Lima et al. 400 (HUEFS); Porto de Sauípe, 12²2'34"S, 37³3'30”W, 22 nov. 2009 (fl.), C. Lima et al. 300 (HUEFS); Santa Cruz Cabrália, 18 mar. 1974 (bot.), R.M. Harley et al. 619 


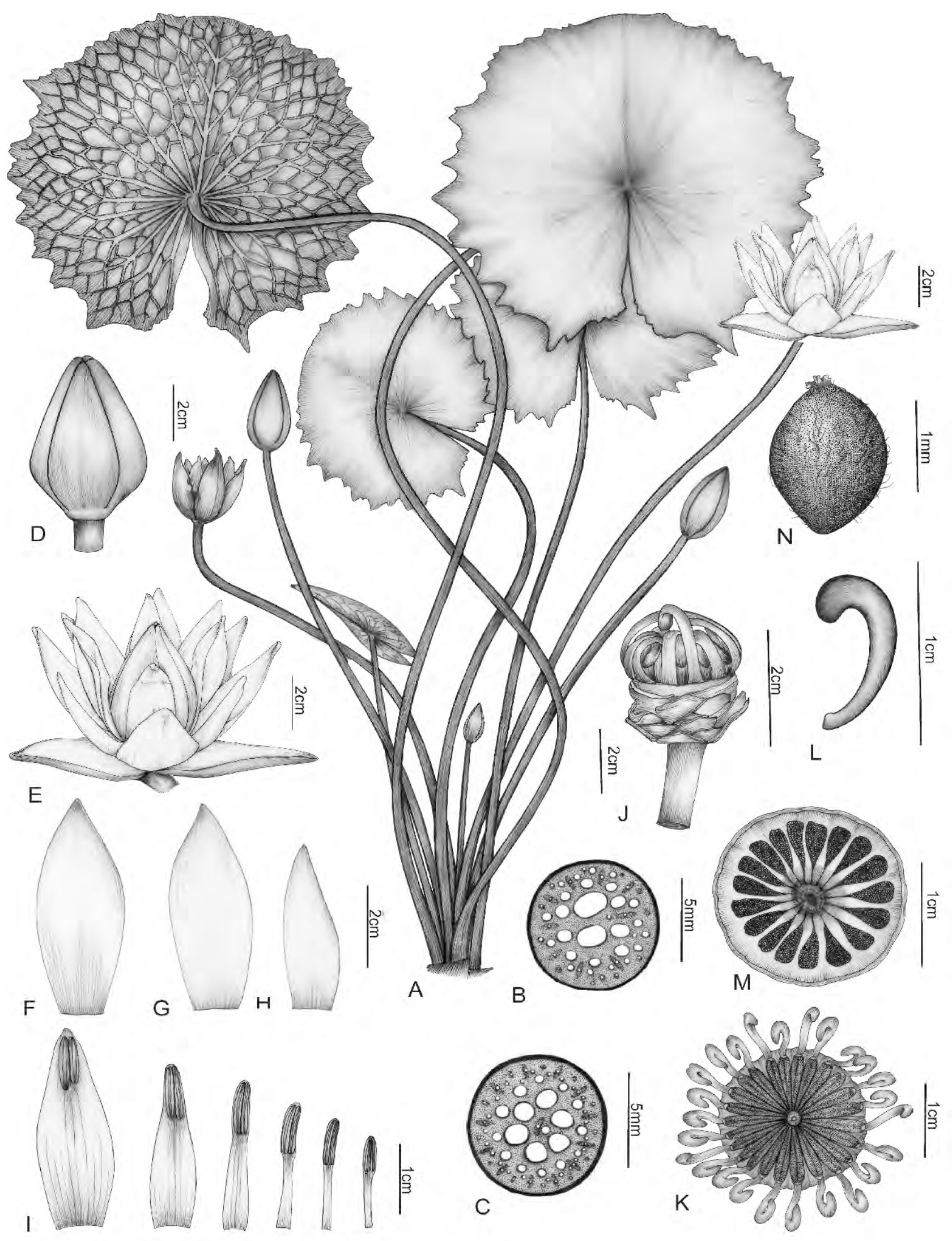

Figura 12. Nymphaea rudgeana (Lima 215): A- hábito; B- corte transversal do pecíolo; C- corte transversal do pedúnculo; D- flor fechada; E- flor aberta; F- sépala; G- pétala maior; H- pétala menor; I- sequência de estames; J- gineceu, vista lateral; K- gineceu, vista frontal; L-apêndice carpelar; M- corte transversal do fruto; $\mathbf{N}$ - semente.

Sitientibus série Ciências Biológicas 12(1): 69-82. 2012. 


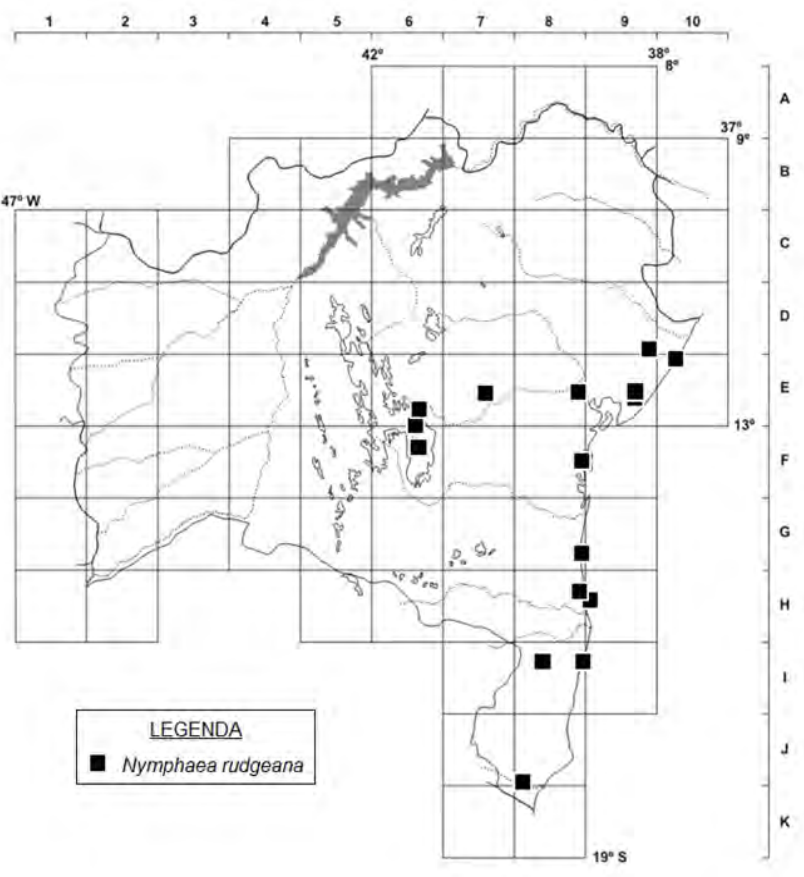

Figura 13. Pontos de coleta de Nymphaea rudgeana na Bahia.
(RB); Tabatã, rodovia BR-101, 1756'43"S, 3951'38'W, 30 abr. 2010 (fl.), C. Lima et al. 332 (HUEFS); Una, rio Serra, entre os municípios de Ilhéus e Una, 1 ago. 2009 (bot., fl.), C. Lima et al. 178 (HUEFS).

Nymphaea rudgeana possui flores com antese noturna. A abertura ocorre por volta das 18:00 horas e o fechamento se dá por volta das 3:00 horas do dia seguinte. Um leve aroma de acetona é liberado, por duas noites consecutivas. Foi observado que as flores são protogínicas, como relatado por Prance \& Anderson (1976).

Amaral (2010) refere o espécime Grupo Pedra do Cavalo 619 depositado no herbário NY como um espécime representativo da espécie $N$. ampla na Bahia. A análise das duplicatas deste espécime depositadas nos herbários ALCB, CEPEC e RB mostraram tratar-se de $N$. rudgeana. Assim sendo, considerou-se neste trabalho que N. ampla não ocorre na Bahia.

\section{Agradecimentos}

Este trabalho é parte da dissertação de mestrado da primeira autora, desenvolvida com bolsa da CAPES. Os autores agradecem, também, ao MCT e à Fapesb pelo apoio às coletas através dos projetos PPBio do Semi-árido e Flora da Bahia. AMG e FARS são bolsistas de produtividade do CNPq. (ver outros artigos para formatação)

\section{REFERÊNCIAS}

Amaral, M.C. 2010. Nymphaeaceae. In: R.C. Forzza, J.F.A. Baumgratz, C.E.M. Bicudo, A.A. Carvalho Jr, A. Costa, D.P. Costa, M. Hopkins, P.M. Leitman, L.G. Lohmann, L.C. Maia, G. Martinelli, M. Menezes, M.P. Morim, M.A.N. Coelho, A.L. Peixoto, J.R. Pirani, J. Prado, L.P. Queiroz, V.C. Souza, J.R. Stehmann, L.S. Sylvestre, B.M.T. Walter \& D. Zappi (eds), Catálogo de Plantas e Fungos do Brasil. Vol. 2. Instituto de Pesquisas Jardim Botânico do Rio de Janeiro, Rio de Janeiro.

APG III 2009. An update of the Angiosperm Phylogeny Group classification for the orders and families of flowering plants. Botanical Journal of the Linnean Society 161: 105-121.

Barbosa, M.R.V; Sothers, C.; Mayo, S.; Gamarra-Rojas, C.F.L \& Mesquita, A.C. 2006. Checklist das Plantas do Nordeste Brasileiro: angiospermas e gimnospermas. Ministério de Ciências e Tecnologia, Brasília.

Bosch, T.; Löhne, C. \& Wiersema, J.H. 2008. Phylogeny and evolutionary patterns in Nymphaeales: integrating genes, genomes and morphology. Taxon 57: 1052-1081.

Caspary, R. 1878. Nymphaeaceae. In: C.F.P. Martius, A.G. Eichler \& I. Urban (eds), Flora Brasiliensis. Vol. 4, pars 2. Frid. Fleischer, Leipzig, p. 120-184, tab. 28-38.

Conad, H.S. 1905. The waterlilies: a monograph of the genus Nymphaea. Publications of the Carnegie Institutions of Washington 4: 1-279.

Feres, F. \& Amaral, M.C.E. 2003. Nymphaeaceae. In: M.G.L. Wanderley, G.J. Sherpherd, A.M. Giulietti \& T.S. Melhen (eds), Flora Fanerogâmica do Estado de São Paulo. Vol. 3. FAPESP/RiMa, São Paulo, p. 441-451.

França, F. 2006. Nymphaeacee. In: A.M. Giulietti, A.A.
Conceição \& L.P. Queiroz (eds), Diversidade $e$ Caracterização das Fanerógamas do Semi-árido Brasileiro. Vol. 1. Instituto do Milênio do Semiárido. Ministério de Ciências e Tecnologia, Brasília.

França, F.; Melo, E.; Góes, N.A.; Araújo, D.; Bezerra, M.G.; Castro, I. \& Gomes, D. 2003. Flora vascular de açudes de uma região do Semi-árido da Bahia, Brasil. Acta Botanica Brasilica 17: 549-559.

Hoehne, F.C. 1948. Plantas Aquáticas. Secretaria da Agricultura de São Paulo, São Paulo.

Lima, C.T. 2011. A Ordem Nymphaeales no Estado da Bahia, Brasil. Dissertação de Mestrado. Universidade Estadual de Feira de Santana.

Prance, G.T. 1980. A note on the pollination of Nymphaea amazonum Mart. \& Zucc. (Nymphaeaceae). Brittonia 32: 505-507.

Prance, G.T. \& Anderson, A.B. 1976. Studies on the floral biology of Neotropical Nymphaeaceae. Acta Amazonica 6: 163-170.

Souza, V.C. \& Lorenzi, H. 2008. Botânica Sistemática. Guia ilustrado para identificação das famílias de angiospermas da flora brasileira, baseado em APG II. Instituto Plantarum, Nova Odessa.

Wiersema, J.H. 1987. A monograph of Nymphaea subgenus Hydrocallis (Nymphaeaceae). Systematic Botany Monographs 16: 46-101.

Wiersema, J.H. 2008. Taxonomy and typification of Nymphaea ampla (Salisb) DC. sensu lato (Nymphaeaceae). Taxon 57: 967-974.

\section{Lista de Exsicatas}

Aona, L.Y.S. 1205B (4); Augusto, W.B. 12 (6); Barreto, O. 34 (5); Belém, R.P. 1232 (5); Brito, H.S. 284 (5); Carvalho, A.M.:
593 (6); Ferreira, J.L. 116 (5); Fonseca, M. 922 (1). Forzza, R.C. 1309 (5); França, F. 1212, 1649, 1753, 1739, 2457 (5), 5239 
(3), 5241, 5001(5); Gomes, C.E. 352 (5); Gomes, F.S. 159 (5); Guedes, M.L. 4617, 9212, 11049, 11404 (5); Grupo Pedra d Cavalo 619 (6); Harley, R.M. 619, 3107 (5), 28441 (6), 28467 (5), 53565 (6), 53781 (5), 54520 (4); Jost, T.: 667 (5); Leite, K.R.B. 363, 440 (5); Lima, C.T. 164-168, 175 (5), 178 (6), 191, 207 (2), 208 (4), 209 (2), 211 (6), 212 (5), 213 (4), 215 (6), 216 (1), 218, 219 (5), 224, $225(3), 226(5), 227,230(3), 231(5), 232,233$ (3), 234, 236 (5), 237 (4), 248 (1), 250 (3), 251 (6), 254, 256, 258-260 (5), 261 (3), 264 (5), 265 (3), 267 (2), 268 (4), 269 (2), 277 (5), 285 (3), 287 (6), 299 (1), 300, 306, 307 (6), 308 (1), 309 (3), 310, 311 (1), 312, 323, 325 (5), 326 (3), 328 (2), 329 (4), 330
(5), 332 (6), 333, 334 (2), 335, 336 (6), 337 (2), 339 (5), 341 (4), 342 (5), 343 (4), 347 (5), 348 (1), 349 (3), 350, 351 (4), 353 (2), 354 (2), 361, 365 (5), 366 (1), 367 (5), 368, 370 (1), 371 (6), 372, 375, 378 (1), 383 (5), 384 (4), 385, 400 (6), 408, 409 (4); Lughadha, E.N. 6015 (5); Melo, E. 1747, 1819, 3154, 3773 (5), 5357(6); Noblick, L.R. 1873 (5); Oliveira, I. 13 (5), 80 (6); Pereira-Silva, G. 8478, 8480 (5); Pinheiro, R.S. 1048 (5); Queiroz, L.P. 1271 (5); Santana. D.L. 82 (6), 95, 100, 102, 108, 120, 666 (5); Santos, T.S. 2986 (5); Senna, L.R. 163 (5); Siqueira-Filho, J.A. 1657 (5); Stannard, B. 2308 (5); Thomas, W.W. $14129(6)$. 